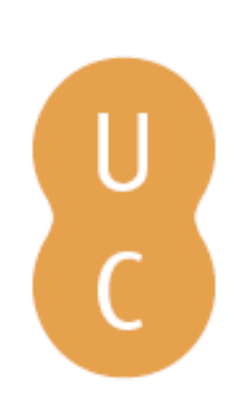

\title{
nombalina
}

\section{La valía de las mujeres en Plutarco}

\author{
Autor(es): $\quad$ Aguilar, Rosa Maria
}

Publicado por: Imprensa da Universidade de Coimbra; Katholieke Universiteit Leuven

URL

persistente:

URI:http://hdl.handle.net/10316.2/32087

DOI:

DOl:http://dx.doi.org/10.14195/978-989-26-0462-6_1

Accessed : $\quad$ 26-Apr-2023 09:58:18

A navegação consulta e descarregamento dos títulos inseridos nas Bibliotecas Digitais UC Digitalis, UC Pombalina e UC Impactum, pressupõem a aceitação plena e sem reservas dos Termos e Condições de Uso destas Bibliotecas Digitais, disponíveis em https://digitalis.uc.pt/pt-pt/termos.

Conforme exposto nos referidos Termos e Condições de Uso, o descarregamento de títulos de acesso restrito requer uma licença válida de autorização devendo o utilizador aceder ao(s) documento(s) a partir de um endereço de IP da instituição detentora da supramencionada licença.

Ao utilizador é apenas permitido o descarregamento para uso pessoal, pelo que o emprego do(s) título(s) descarregado(s) para outro fim, designadamente comercial, carece de autorização do respetivo autor ou editor da obra.

Na medida em que todas as obras da UC Digitalis se encontram protegidas pelo Código do Direito de Autor e Direitos Conexos e demais legislação aplicável, toda a cópia, parcial ou total, deste documento, nos casos em que é legalmente admitida, deverá conter ou fazer-se acompanhar por este aviso. 


\title{
Puilosophy in Society \\ Virtues and Values in Plutarch
}

\author{
José Ribeiro Ferreira \\ LUC VAN DER STOCKT \\ Maria do Céu Fialho
}

Editors

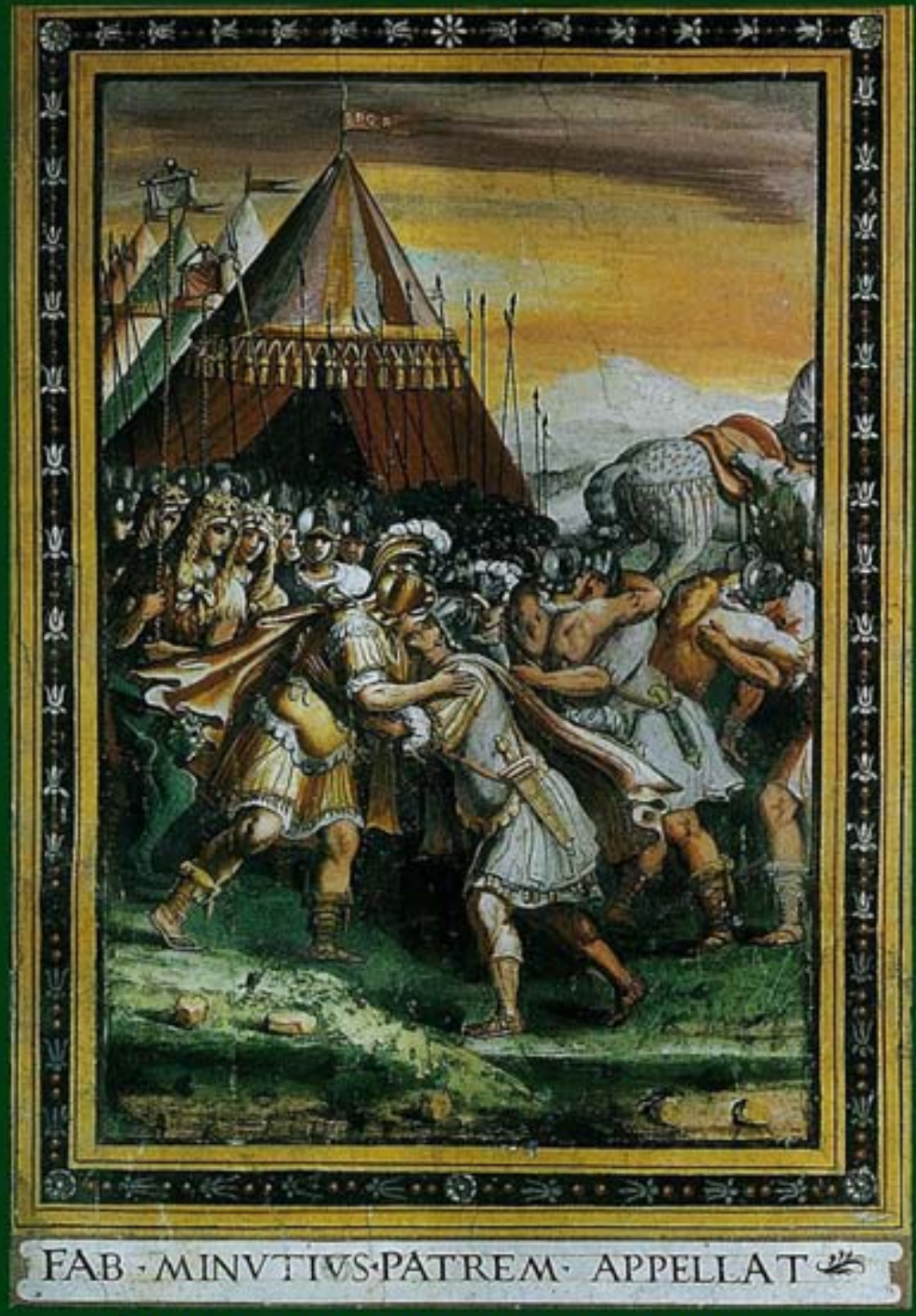

KATHOLIEKE UNIVERSITEIT LEUVEN IMPRENSA DA UNIVERSIDADE DE COIMBRA Leuven-Coimbra, 2008 
(Página deixada propositadamente em branco) 
José Ribeiro Ferreira, Luc van der Stockt \& Maria do Céu Fialho

EDITORS

\section{PhILOSOPHY IN Society}

\section{Virtues and Values in Plutarch}

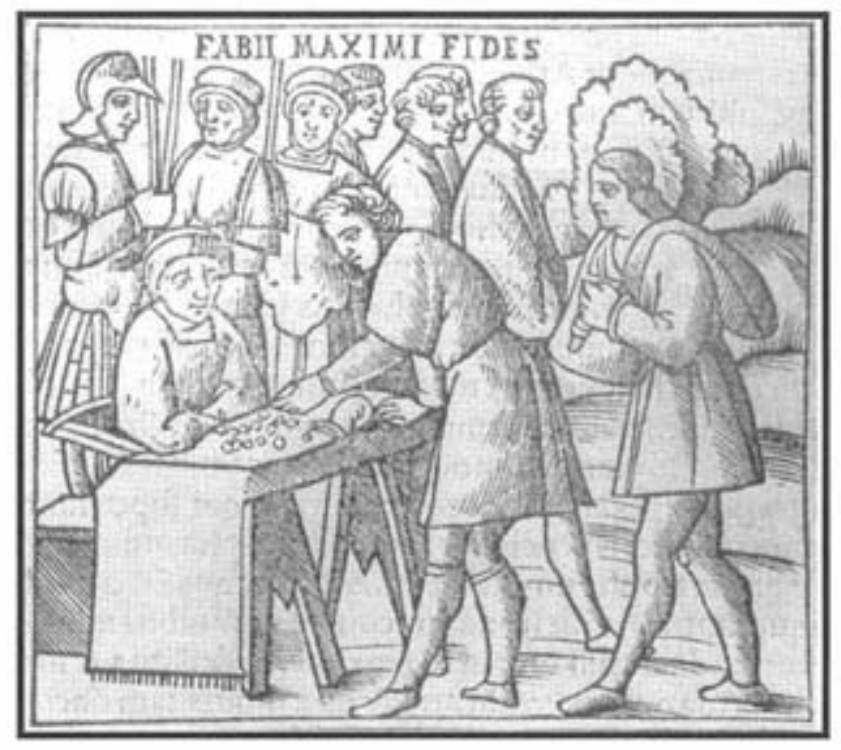

Fabius Maximus' Loyalty

Vitae Plutarchi Cheronei novissime post Jodocum Badium Ascensium longe diligentius repositae maioreque diligentia castigatae, cum copiosiore verioreque indice, nec non cum Aemilii Probi vitis, una cum figuris, suis locis apte dispositis, Venetiis 1516 , fol . 65v

\section{LEUVEN - CoIMBRA \\ 2008}

KATHOLIEKE UNIVERSITEIT LEUVEN

IMPRENSA DA UNIVERSIDADE DE COIMBRA 


\title{
First published 2008
}

\section{(C) Universiteit KATHOlieke Leuven \\ (c) Universidade Coimbra}

\author{
Published by \\ IMPRENSA DA UNIVERSIDADE COIMBRA \\ Imprensa da Universidade de Coimbra \\ Rua da Ilha, $\mathrm{n}^{\circ} 1$ \\ 3000-033 Coimbra (Portugal) \\ Email: imprensauc@ci.uc.pt \\ URL: http://www.uc.pt/imprensa_uc
}

ISBN: 972-989-8074-73-7

Legal Deposit: MA-140-2009

\author{
Printed in Spain by \\ IMAGRAF IMPRESORES, S.A. \\ c/ Nabucco 14 \\ 29006 Málaga \\ Tfno. 952328597
}

\section{Frontispiece:}

Fabius Maximus and Minucius (Francesco da Siena, Grottaferrata, Palazzo Abbaziale). We are grateful to the Archimandrita of the "Monastero Esarchico di Santa Maria di Grottaferrata", P. Emiliano Fabbricatore, for the authorization to reproduce this picture. 


\section{La valía de las mujeres en Plutarco \\ Rosa M" AgUILAR \\ UNIVERSIDAD COMPLUTENSE}

\section{A modo de introducción}

Como de todos es bien conocido Plutarco dejó en el prólogo -y también dedicatoria- de su Mulierum virtutes, escrito para su amiga Clea, una afirmación rotunda sobre su creencia entre la igualdad en virtud de hombres y mujeres: $\epsilon$ is tò $\mu i a \nu$ €ival kaì

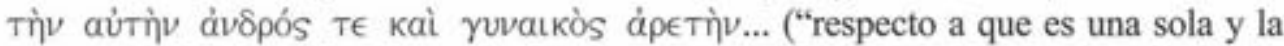
misma la virtud del hombre y la de la mujer...", Mul. virt., 242F ), prosiguiendo luego con ejemplos en los que podrían equipararse fácilmente hombres y mujeres, como el de la pintura, donde los más famosos pintores han representado parecidamente a unos y a otras ${ }^{1}$, o los de la poesía y la mántica con parangones entre poetas de uno u otro sexo, como Safo y Anacreonte o profetas como Sibila y Bacis ${ }^{2}$.

Podria pensarse que este juicio tan positivo del queronense sobre las mujeres, no siempre compartido por los autores y filósofos de la antigủedad, fuera fruto tardío y quizá asi determinado por una mayor madurez en su carácter, pero nosotros creemos que su juicio se mantuvo siempre parecidamente favorable y, por eso, intentaremos ahora exponer algunos otros ejemplos de mujeres y sus virtudes a lo largo de su obra, si bien es verdad que mucha parte de lo que nosotros tratamos aquí suele fecharse como compuesto en la última década de su vida, la más fructífera ${ }^{3}$.

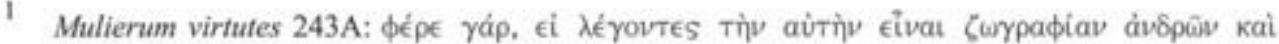

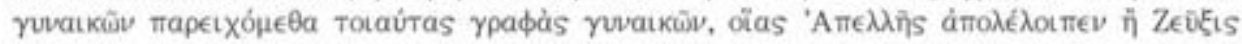

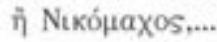

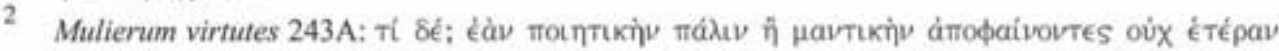

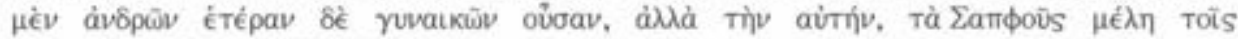

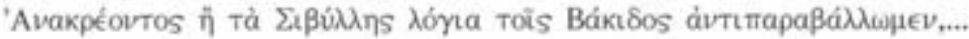

3

Véase PH. A. StADter, 1965, p. 2, respecto a este tratado y al Amatorius.

José Ribeiro Ferreira, Luc Van der Stockt \& Maria do Céu Fialmo (Edd.), Philosophy in Society - Virtues and Values in Plutarch, Leuven-Coimbra, 2008, pp. 9-18. 


\section{Algunos ejemplos}

\subsection{Ismenodora, la enamorada.}

Ismenodora es un personaje plutarqueo bien conocido. En cierta medida es la protagonista del Amatorius o Diálogo sobre el amor, o al menos es la causa de que alli se hable sobre el amor. ¿ Fue un personaje histórico, sacado de la realidad? Presumiblemente debería ser asi ${ }^{4}$, ya que el narrador de la historia, Autobulo, el hijo de Plutarco, la sitúa en una visita de sus padres, recién casados, a Tespias a donde habian ido a las fiestas Erotidias para hacer sacrificios al dios como remedio a algún contratiempo matrimonial acaecido hacía poco. Plutarco oye la historia sobre el enamoramiento de Ismenodora por el joven Bacón, según se va desarrollando, a través de las noticias que se suceden durante la conversación con sus interlocutores, suceso éste sin duda inusitado en aquel entonces, aunque ya estemos lejos en el tiempo de la Atenas restrictiva hacia la presencia pública de la mujer según la información de Tucidides ${ }^{5}$. Pues bien, aunque esta historia, casi novelita rosa, sea bien conocida de todos, no dejaremos de irla recordando ahora para seguir el hilo de nuestra argumentación.

2.1.1. Ismenodora es una joven viuda y, además, bella y rica. Mantiene una buena amistad con otra mujer, que presumiblemente sería también viuda, la madre de Bacón. Ésta última está buscando esposa para su hijo, -de ahí que supongamos su estado de viudez-, e Ismenodora la acompaña en sus maquinaciones para lograr sus objetivos y, a fuerza de visitarla en su casa, conoce a Bacón y se enamora de él. Pero, de otra parte, el muchacho, que visita de continuo la palestra, tiene sus pretendientes masculinos como era de suponer, -Pisón, el más importante-, y se ve compelido entre dos frentes, las pretensiones masculinas y este nuevo amor femenino de Ismenodora (749D-E). ¿Qué edad tendría Ismenodora? La communis opinio le atribuye treinta años lo que a mi me parece a todas luces una exageración. Aunque la mujer se casara habitualmente a los quince años y su marido tuviera no menos de treinta, no era inhabitual que el marido fuera aún mayor, especialmente en matrimonios concertados entre parientes, e Ismenodora podría haberse quedado viuda bastante más joven. La edad de Bacón era presumiblemente de dieciocho a veinte años por ser un efebo ${ }^{6}$. Si la diferencia de edad parecía un grave inconve-

Véase R. FLACELIĖRE, 1980, pp. 34-35 : "...Plutarque a su utiliser tout au long de ce dialogue l'histoire d'Isménodore et de Bacchon, sans doute inventée par lui »

Véase Th. II 45, 2 para las palabras de Pericles sobre las mujeres viudas. Disiente Plutarco en Mul. Virt. 242E.

6 W. C. Helmbold en su edición del Amatorius, Loeb Class. Libr. IX, p. 331, n. a , comenta la cita de Hesiodo (Hes. Op. 696-698) en 753A sobre la edad adecuada para el matrimonio en el sentido de que, si se casaban Ismenodora y Bacón, invertirian las edades convenientes, treinta para el hombre y diecisiete para la mujer. Por otra parte en 749D el narrador, Autobulo, la califica como joven, para subrayar, a pesar de ello, su serio comportamiento de viuda. 
niente otro no menor era la riqueza de esta mujer. Y además no pesa menos como argumento negativo la capacidad de iniciativa de Ismenodora en un asunto como el matrimonio en el que, habitualmente, era el padre o los parientes varones quienes tenian la misión de tomar decisiones. Así las cosas, veamos las posiciones de cada uno respecto a la desigual boda.

2.1.2. Las mujeres. Sólo aparecen en el relato dos. De la primera, Ismenodora ${ }^{7}$, ya hemos hablado y no hay nada que añadir de momento. De la madre de Bacón debemos acentuar su temor ante la nobleza y riqueza de la casa de Ismenodora que no le resultaban conformes a la suya y de su hijo (749E).

2.1.3. Los hombres. Son muchos aquí los que opinan sobre la boda. Bacón, en principio, no parece totalmente opuesto. Sin embargo, algunos de sus compañeros de cacería le influían negativamente alegando la edad de Ismenodora y haciendo bromas de que se fuera a casar con una viuda. Él, entonces, se sentia avergonzado ante esta boda desigual (749E). Antemión y Pisias son otros amigos de más edad en quienes el muchacho confiaba respecto a consejo y decisión. El primero era un primo suyo mayor y el segundo el más serio entre sus amantes y, naturalmente, opuesto a este matrimonio. Por eso influía en Antemión para que aconsejase a Bacón renunciar a Ismenodora. Éste, por su parte, no estaba nada convencido de que el joven debiera perder tal oportunidad sólo porque permaneciese más tiempo ajeno a estas cosas y frecuentando las palestras ${ }^{8}$. Entre todos los amigos reunidos con Plutarco en esta escena campestre en el monte Helicón junto a las Musas y lejos del ruido de los concursos en Tespias, se añaden Dafneo en apoyo de Antemión y en el de Pisias Protógenes ${ }^{9}$. Éste último se manifestará partidario del amor por los muchachos y tremendamente beligerante contra el amor conyugal. Por último, el propio Plutarco, el personaje capital, quien pronunciará tres discursos a favor del amor en el matrimonio, mostrando un claro rechazo del otro amor ${ }^{10}$. No vamos a reproducir todos los argumentos, desde luego, ya que el motivo inicial de la discusión -el enamoramiento de Ismenodora y Bacón- se desborda en teorías sobre una u otra clase de amor. Nuestro propósito, mucho más modesto, es seguir la figura de Ismenodora, sus virtudes y valores como mujer, a través de lo que se habla en este círculo de amigos.

En las posiciones contrarias a Ismenodora la más agria, sin duda, es la de Protógenes por su apoyo a ultranza a Pisias y por su alineamiento a favor del amor

De ella como personaje femenino relevante nos ocupamos también hace años en "Buenas y malas mujeres de la antigua Grecia", Ros^ Mả. Aguilar, 1996a, pp. 91-92.

749F-750A. En realidad Antemión se expresa más crudamente: o̊mws à

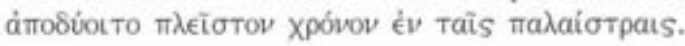

De Tarso. Personaje importante en el De sera muminis vindicta.

De estos discursos nos hemos ocupado hace ya tiempo: Rosa M". AGuILAR, "La mujer, el amor y el matrimonio en la obra de Plutarco", Faventia, 12-13 (1992) 308-314. 
homosexual como el único verdadero. Así, desde que se presenta, no cesaba de hablar mal de la viuda (753A), decía que invertía con sus pretensiones la edad aconsejada por Hesíodo para hombre y mujer en el matrimonio (753A) y, en su indignación por la osadía de su declaración amorosa, pensaba que nada podría impedir que asumiera el papel masculino en su relación con Bacón, como rondar cantando a su puerta o coronar sus retratos con guirnaldas y pegarse con las rivales entre otras acciones propias de los hombres enamorados (753B). Pisias, en cambio, consideraba como lo más peligroso la riqueza de la mujer, riqueza que lograría que ella tuviese el dominio en esa relación con un muchacho necesitado aún del pedagogo $(752 \mathrm{~F})^{11}$, -pues pensaba que la riqueza hace a las mujeres muelles, inseguras $y$ vanas-, aunque su programa ya había sido expresado un poco antes: no es conveniente que las mujeres decentes amen ni sean amadas (752C).

Plutarco ante tal número y clase de censuras toma la defensa de Ismenodora ${ }^{12}$, animado también por Antemión (753E) y, si bien éste le ha indicado que defienda el asunto de la riqueza de Ismenodora, él, sin embargo, va más allá y empareja riqueza y amor. Su argumentación parte, pues, de que no se podrá rechazar a Ismenodora por su amor y su riqueza. Tampoco porque sea joven y bella ${ }^{13}$ ni porque su linaje sea ilustre (753E). Más adelante retoma el asunto de su riqueza y dice que si elegir a una mujer por su fortuna en lugar de por su virtud y linaje es innoble, es absurdo rechazarla por aquella cuando existe además virtud y linaje (754A-B). Después argumenta que ella tiene la edad y el momento de parir como él la de engendrar, insistiendo luego en que Ismenodora está, por lo que sabe, en la flor de la edad y, ante la sonrisa irónica de Pisias, añade que no es mayor que sus propias rivales ni tiene canas como alguno de los pretendientes masculinos de Bacón (754C). En el matrimonio los comienzos son dificiles, dice, sobre todo cuando surge el amor y ambos quieren mandar y ninguno obedecer. $Y$ con símiles sacados de la vida diaria: la nodriza manda sobre el niño, el maestro sobre el muchacho, el gimnasiarco sobre el efebo, el amante sobre su joven amigo y cuando éste ya es un hombre le rige la ley y el general, porque nadie es independiente y autónomo... aduce nuestro autor ¿qué tiene de raro que una mujer inteligente aunque de más edad, gobierne la vida de un hombre al ser útil por su inteligencia y dulce por su cariño? Y remacha su razonamiento con un ejemplo mítico: Heracles casó a Mégara, su mujer de treinta y tres años, con su sobrino Yolao quien sólo contaba con dieciséis años de edad (754D-E).

2.1.4 Desenlace Es entonces, cuando Plutarco había terminado su argumentación, cuando se presenta un amigo de Pisias a caballo, a todo galope, para contarle lo que llamaremos el rapto de Bacón por obra de Ismenodora, rapto que en el que

\footnotetext{
11 Exageración a todas luces, ya que la efebía era una mayoría de edad.

12

13

Es su primer discurso que ocupa casi todo el c. 9 (753B-754E).

Nuevamente, como en 749D se llama joven a la viuda.
} 
quizá éste no fuera tan inocente ${ }^{14}$. No vamos ahora a entrar en detalles sobre la indignación del pueblo de Tespias ante el hecho o la misma de Pisias y sus partidarios. Sólo diremos que todos acabaron por calmarse y el final fue feliz pues terminó en boda. Lo que nos interesa ahora es ver cuáles son los valores de la enamorada a partir de los razonamientos de nuestro autor:

Ismenodora es joven y bella y de un buen linaje; siente amor por Bacón; es además rica, pero su riqueza no debe ser un obstáculo para esta unión, porque hay virtud y linaje junto a la riqueza; la diferencia de edad no debe importar si la mujer es inteligente y afectuosa en su comportamiento.

En resumen, Plutarco cree que para formar un matrimonio lo importante es la virtud basada en el amor, virtud que no se ve impedida en su desarrollo ni por familia ni por fortuna. Al principio presenta juventud y belleza como cualidades de esta mujer, pero ni éstas ni tampoco la desigualdad de edades son elementos esenciales del amor según hemos visto en el razonamiento final.

\section{2. Cornelia, la esposa.}

La Cornelia ${ }^{15}$ que hemos elegido, entre otras posibles candidatas, como prototipo de esposa es la quinta y última mujer de Pompeyo. Su matrimonio tuvo razones politicas -se trataba ahora para Pompeyo de alejarse de César y su populismo y arrimarse al partido de los optimates- pero su comportamiento con el esposo, mucho mayor, en las difíciles circunstancias de su final la sitúan como uno de los ejemplos más señeros.

2.2.1. Aunque llegó al matrimonio con Pompeyo ya viuda, de Publio, hijo de Craso, muerto en la campaña contra los partos, era todavia una mujer joven. De ella Plutarco hace una descripción, incluso un retrato, uno de los escasos ejemplos en su obra $^{16}$. Así leemos que esta joven mujer tenía otros encantos además de la belleza de su juventud, pues era experta en literatura, en música y en geometria y estaba acostumbrada a seguir con provecho las obras de los filósofos. Pero por encima de eso su mayor virtud, resalta Plutarco, era el carecer de pretensiones y pedantería, como les suele ocurrir a otras mujeres jóvenes que practican tales estudios. Se le criticaba a Pompeyo, no obstante, este matrimonio por lo desparejo de las edades y, también a ella que en circunstancias difíciles se confiara tan sólo a él, haciendo que descuidase los asuntos de la ciudad ${ }^{17}$.

\footnotetext{
14 Es el pensamiento de Soclaro, 755C-D, rechazado vivamente por Antemión de seguido.

15

Sobre Cornelia véase S. P. HALEY, 1996, pp. 103-104.

16 F. LE CoRsu 1981, p. 32.

17 Pomp. 55,1-5.
} 
2.2.2. La grandeza de su conducta como esposa se muestra, en cambio, en los momentos graves, cuando se ha producido el enfrentamiento entre César y Pompeyo y luego la derrota de éste. Cornelia había seguido a su esposo en su campaña en Grecia y le estaba esperando en Lesbos ${ }^{18}$. Al principio llegaron alli noticias confusas sobre su primera victoria, de suerte que estaba tranquila. Por eso, la llegada de Pompeyo en una nave huyendo tras la derrota le produjo una enorme conmoción y desmayo, hasta el extremo de atribuirse a ella y a su terrible destino todo lo que ahora le sucedía a su esposo. Reacciona pronto sin embargo, pide que vengan al puerto los servidores de la casa con sus pertenencias que necesitarían en la huída y acompaña a su esposo hasta su trágico final en Egipto. Ella fue quien, finalmente, se hizo cargo de sus cenizas y las depositó en su villa de Albano ${ }^{19}$.

2.2.3. En la figura de Cornelia encontramos destacada su formación intelectual por encima y más allá de juventud, belleza o riqueza, -la cual ni siquiera se menciona-, aunque si la nobleza de su nacimiento por cuanto concernía a su padre, cuya conducta también señala nuestro autor como irreprochable ${ }^{20}$. Los datos que ha ofrecido Plutarco sobre Cornelia, son, en cierta medida, coincidentes con los de la bella Ismenodora. Sin embargo, aunque Plutarco no haga mención expresamente de ello, la fidelidad al esposo en lo bueno y en lo malo seria, a nuestro ver, a sus ojos su mayor virtud, como ocurre también en el caso de Porcia, la mujer de Bruto, otro modelo de esposa ${ }^{21}$.

\section{3. Timóxena, la madre.}

La figura de la esposa aparece en muchas ocasiones en la obra de Plutarco. La suya propia ya figura mencionada, pero sin su nombre, en el prólogo que hace el hijo, Autobulo, a la narración del Amatorius, como acabamos de ver. Es una escena muy humana, la pareja de recién casados, Plutarco y su esposa, de visita en la cercana Tespias, para hacer un sacrificio al dios del amor por algún motivo personal. Pero eso es todo. Por supuesto que ni ella ni otra mujer alguna participarán en el diálogo que luego se va a desarrollar sobre el amor $-\mathrm{y}$ puede que ella tuviera algo que opinar ya sobre el amor conyugal-, pero ése no era escenario para una mujer. Sin embargo, si conocemos que se llamaba Timóxena por el escrito de la Consolatio ad uxorem donde Plutarco alude a que él había puesto su nombre a la hijita, nacida en último lugar tras cuatro varones ${ }^{22}$, e incluso tenemos noticia de que habría escri-

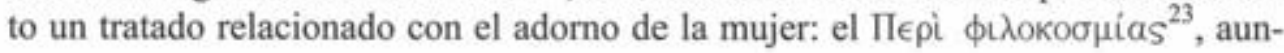

Pomp. 66.3.

Pomp. 74-80.

Pomp. 55.5.

Cato Minor 73.

$608 \mathrm{C}$. 
que los descreídos prefieran pensar que sería obra del mismo Plutarco y que, amablemente, le habría cedido su autoria ${ }^{24}$.

2.3.1. Sin embargo, es gracias a la carta de consolación como podemos conocer más noticias sobre Timóxena, que la retratan fielmente como esposa y como madre, cosa que ahora nos ocupa. La Consolatio ad uxorem es un tratado en cierta medida tradicional, pues no se puede evadir totalmente de la estructura y rasgos de este género literario. Pero, de otra parte, como ya ha sido repetidamente señalado, las circunstancias en que se compuso le dan una singularidad especial. Uno, porque la muerte de la niñita sorprendió a Plutarco fuera de su casa y otro, porque no era nadie ajeno a él quien había muerto. Así, la composición de esta carta apenas tiene citas literarias ${ }^{25}$, sólo las que él podría recordar fácilmente de memoria y quizá por eso mismo más preciadas. Además, esa ausencia de la casa en el momento de la muerte de la niña también le conduciría seguramente a una afectividad más expresiva.

2. 3.2. Rasgos y virtudes de Timóxena como madre según las palabras de Plutarco en la carta de consolación:

Alegría por el nacimiento de una niña después de cuatro hijos varones $(608 \mathrm{C})$.

Han educado los dos juntos a todos sus hijos en la casa (608C).

Firmeza al perder al mayor de los hijos y luego a otro, a Querón (609D).

Crianza de la niña a su pecho, incluso en medio de grandes inconvenientes (609D-E).

A diferencia de otras madres, que sólo toman en brazos a sus hijos cuando las sirvientas los han bañado, ella se ha implicado siempre en el cuidado de los suyos (609D).

2.3.3. El duelo. Todo su comportamiento como madre, y madre en duelo, corre parejo con su conducta sensata y modesta en la vida diaria. Por eso no tiene nada de raro que no se vista de luto ni adopte otros signos externos propios de éste, porque nunca se ha vestido especialmente para ir al teatro o a las procesiones y siempre ha considerado innecesario el lujo (608F-609B), como también es conocida su modestia y la simplicidad de su modo de vivir (609C-D).

A modo de carta dedicada a Aristila. Cf. Coniugalia praecepta 145A, donde alude a ella: Пє

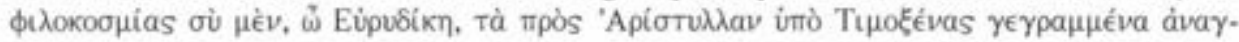

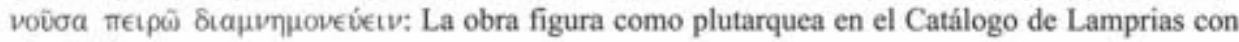
el n. 113 . Véase P. Impara y M. MANFredini, 1991, p. 39, n.109, donde citan la opinión de Wilamowitz en tal sentido.

25 Dos citas son de poetas: Euripides y Teognis (E., •Phaëth. fr. 785 Nauck $^{2}$ en $608 \mathrm{C}$ y Thgn., 427 en 611 F) y otra de una fábula de Esopo (462 Perry) en 609F. 
2. 3. 4. La fe en el Más Allá. Para Plutarco esa serenidad de conducta en su mujer está basada no menos en la creencia en la doctrina de sus padres ${ }^{26}$ y en los símbolos místicos de las celebraciones de Dioniso que ambos han compartido ${ }^{27}$.

2. 3. 5. Se podría concluir que para nuestro autor son sencillez, modestia, amor y religiosidad elementos imprescindibles en la conducta de una madre, pero que todos ellos van ligados asimismo con o son consecuencia de la forma de comportamiento de la esposa.

\section{Unas reflexiones finales}

Parece evidente, por lo que hemos ido viendo, que en Plutarco no hay lugar para la mujer amazona. Lo más cercano, por su libertad de iniciativa, sería el caso de Ismenodora, pero tampoco sería exactamente asi porque, al fin y al cabo, ya habia estado antes sometida al yugo del matrimonio. Resulta así impensable, creemos, que Plutarco pudiera presentarnos algún caso de virtud femenina ligado al comportamiento de la joven parthenos ${ }^{28}$. Sin duda alguna la mujer en esa etapa de su vida carece de un estatus que sólo adquirirá como mujer casada, cuando pase de las manos del padre a las del marido. La confirmación se encuentra, a nuestro ver, en las hazañas de las mujeres individualmente consideradas en el Mulierum virtutes. Esas historias, algunas repetidas en el Amatorius, como la de Camma (768B ss.) y la de Empona, $(770 \mathrm{D} \text { ss. })^{29}$ terminan con la victoria de la mujer en la defensa de su marido, victoria que lleva generalmente aparejada la muerte. Hay un caso, sin embargo, el de Aretafila (Mul. virt., 255E ss.) en el cual a ésta, tras haber librado a su patria, Cirene, del tirano Nicócrates, sus conciudadanos le ofrecen participar en el gobierno de la ciudad, cosa a la que ella renuncia. Sin embargo, como subraya Plutarco al comienzo del relato, aunque era bella, parecía sobresaliente por su inteligencia y no inexperta en la habilidad politica ${ }^{30}$, como ha demostrado en su actuación pero, cuando al fin logra la venganza, no acepta esa participación en el gobierno. Muy al contrario, se retira al gineceo y termina sus días en el telar, siguiendo el modelo tradicional de la mujer ${ }^{31}$, lo cual sin lugar a dudas parece merecer la aprobación de nuestro autor.

26

27

28

29

30

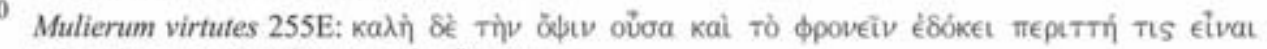

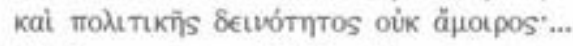

Véase Amatorius 756B.

Un apoyo a la fe en los misterios de Dioniso como vemos por esta iniciación mencionada se comprueba en Quaest. conv, 636D-E. Sobre este tema véase A. JiMÉNEZ SANCristóBAL, 2001, pp. 143 154 y A. Bernabé Pajares, 2001, pp.5-22.

Siempre subyace la idea de la Pandora hesiódica, origen de todos los males, incluso en Plutarco.

A este respecto Ph. A. Stadter en Plutarch s Historical Methods. An Analyse of the Mulierum Virtutes, 1965, p. 7 subraya que: "Plutarch's exaltation of woman and of conjugal love is unique in classical Greek literatur..."

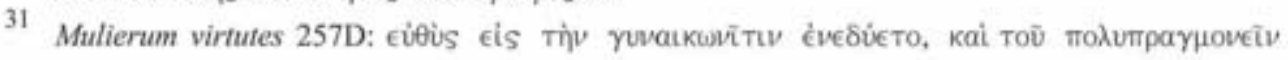


Esta aprobación podría poner el colofón a nuestro estudio.

\section{REFERENCIAS BiBLIOGRÁFiCAS}

AgUILAR, R. M",

- "La mujer, el amor y el matrimonio en la obra de Plutarco", Faventia, 12-13 (1992) 307-325.

- "Buenas y malas mujeres de la antigua Grecia", Enrahonar, 26 (1996) 81-94 (a).

- Plutarco, Escrito de consolación a su mujer en Obras morales y de costumbres (Moralia), Introducciones, traducciones y notas por-_ Madrid Gredos, 1996 (b).

- Las mujeres en la Vida de Pompeyo en InÉs CALERo y Ma. Ángeles Durán, 2002, pp. 190-207.

Bernabé Pajares, A.,

- La experiencia iniciática en Plutarco en A. PÉRez Jiménez y F. CASAdesús Bordoy (eds.), 2001, pp. 5-22.

CALERo, I. \& DURÁN, M". A. (eds.),

- Debilidad aparente, fortaleza en realidad. La mujer como modelo en la Literatura griega antigua, Universidad de Málaga, 2002.

HALEY, S. P,

- The five Wives of Pompey the Great en I. MCAUSLAN y P. WALCOT, 1996, pp. 103-113.

JIMÉNEZ SANCRISTÓBAL, A.,

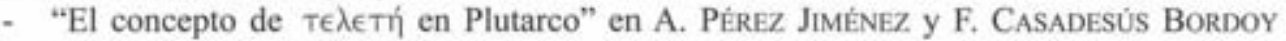
(eds.), 2001, pp. 143-154.

Flaceliére, R.,

- Plutarque, Oetwres morales, X, Dialogue sur l'amour, Paris, Les Belles Lettres,1980.

IMPARA, P. y MANFREDINI, M.,

- Plutarco. Consolazione alla moglie. Introduzione, testo crittico, traduzione e commento a cura di..., Napoli, D'Auria, 1991.

LE CORSu, F.,

- Plutarque et les femmes dans les Vies Paralleles, Paris, Les Belles Lettres, 1981.

LÓPEZ SALVÁ, M.,

- Virtudes de mujeres en Obras morales y de costumbres (Moralia), III, Introducciones, traducciones y notas por — Madrid Gredos, 1987.

MCAUSLAN, I. y WALCOT, P. (eds.),

- Women in Antiquity, Oxford University Press, 1996.

Pérez Jiménez, A. y Casadesús Bordoy, F. (eds.),

- Estudios sobre Plutarco: misticismo y religiones mistéricas, Madrid, 2001.

StAdTER, PH. A.,

- Plutarch's Historical Methods. An Analyse of the Mulierum Virtudes, Harvard University Press, 1965.

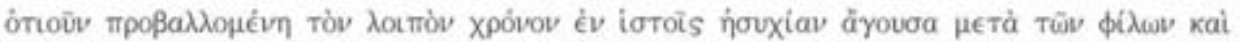

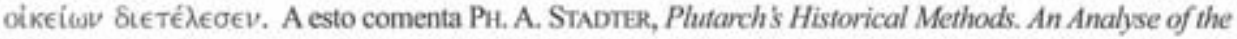
Mulienum Virtutes, 1965, p. 102: "Little wonder that Plutarch compares her with the ancient heroines". 


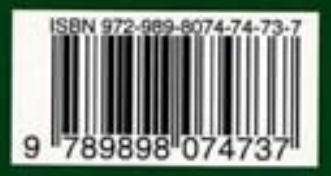

